\title{
Relationship of cataract to radiation sensitivity
}

\author{
NICHOLAS A P BROWN,' G ADRIEN SHUN-SHIN,' PAUL LEWIS, 2 \\ WILLIAM A CRAMP, ${ }^{2}$ COLIN ARLETT, ${ }^{3}$ JANE COLE, ${ }^{3}$ \\ ALASTAIR P W WAUGH, ${ }^{3}$ AND GABRIELLA STEPHENS \\ From the 'Nuffield Laboratory of Ophthalmology, Oxford; the ${ }^{2}$ Department of Histopathology, Royal \\ Postgraduate Medical School, London; and the ${ }^{3}$ MRC Cell Mutation Unit, University of Sussex
}

SUMMARY Considerable exposure to radiation always causes posterior subcapsular cataract (PSC). This investigation was conducted to ascertain whether cellular hypersensitivity to radiation may be identified as a possible cause of cataract in persons exposed to low levels of radiation. Patients were studied in whom PSC had followed probable exposure to low levels of radiation or in whom PSC had developed before the age of 60 without known exposure. The patients with cataract were compared with age and sex matched controls without cataract. Radiation sensitivity was estimated by measuring clonal growth of skin fibroblasts and peripheral blood lymphocytes after exposure to graded doses of radiation and by measuring postirradiation reconstruction of separated nuclear material from lymphocytes. The results show variations in the level of radiation sensitivity between the patients, without significant differences from the controls. It is concluded that radiation hypersensitivity, as tested by the methods used in this study, is not normally associated with the development of posterior subcapsular cataract.

The lens of the eye is unusual in that it grows at a steady rate throughout $\operatorname{life}^{1-3}$ by mitosis of the germinal epithelium at the lens equator and the formation of new fibre cells on the surface of the lens cortex. Cessation of growth is observed in cataract, particularly in subcapsular cataract. ${ }^{1+5}$

The morphology of cataract developing in the adult is divisible clinically into three major categories: cortical, nuclear, and subcapsular. It is probable that the mechanism of cataract formation is different in each of these three categories, with the common end result of increased light scattering in the lens. Biochemical research into mechanisms of cataract formation has been intensive and a large volume of knowledge now exists. ${ }^{\circ}$ This information relates largely to cortical and nuclear cataract, with less known about subcapsular cataract.

Spontaneous posterior subcapsular cataract (PSC) is described as senile, or presenile, according to the age of the patient. Alternatively PSC may be second-

Correspondence to N A P Brown, FRCS, Nuffield Laboratory of Ophthalmology. Walton Street, Oxford OX2 6AW. ary to other eye disease, such as uveitis, ${ }^{7}$ retinal detachment, ${ }^{8}$ and other retinal diseases. In these cases it is described as complicated cataract. Other causes are metabolic disease and drug induction by corticosteroids. ${ }^{910}$

A significant external cause of PSC is ionising radiation by $x$ rays ${ }^{11}$ and by neutron radiation..$^{12}$ Chronic exposure to low $x$ ray dosage has also been implicated..$^{14}$ Absorbed radionuclides are another possible cause. ${ }^{15}$ PSC occurring 'naturally' and those cases induced by radiation have a very similar clinical morphology (Figs. 1 and 2) and are also histologically similar. ${ }^{411416}$ It appears that the primary defect is in the germinal epithelium, which fails to undergo normal mitosis to produce new lens fibres and instead produces granular material, which is seen as cataract and is observed histologically in the subcapsular region.

Thus failure of mitosis can account for both the histology and for the cessation of growth of the lenses developing PSC. In the case of radiation induced cataract it is reasonable to assume that these changes occur because of damage to the DNA of the germinal 


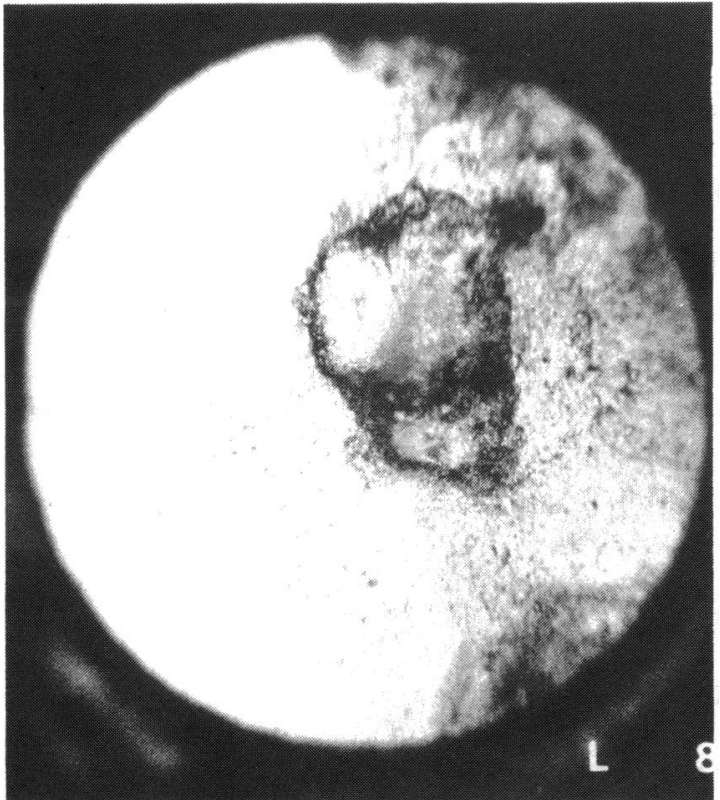

Fig. 1 Posterior subcapsular cataract in one of the Christmas Island personnel photographed on the Oxford retroillumination camera.

epithelium of the lens. In those cases of PSC occurring 'naturally' it is possible that there has been a mutagenic change in DNA affecting mitosis and/ or protein synthesis. The cause of this change is obscure, but it could conceivably have occurred as a result of abnormal sensitivity of the individual to radiation. The radiation responsible may have been either normal background radiation, or other exposure to low doses of radiation that would not normally be considered cataractogenic. ${ }^{17}$

Complicated cataracts are probably different in origin and have a different histology: capsular permeability being implicated in uveitis ${ }^{7}$ and subcapsular fibroplasia in retinal detachment. ${ }^{\times}$The mechanism of drug induced cataract by corticosteroids is suggested to be due to binding of the drug to the protein of the lens fibre. ${ }^{1 \mathrm{x}}$

The individual variation in susceptibility of cancer patients to skin damage during radiation treatment is known to be considerable. Occasionally such susceptibility is so profound as to interfere with a course of treatment. It was such a clinical observation that led to the recognition of extreme cellular sensitivity to $x$ rays, implying defective DNA repair, in ataxia-telangiectasia. ${ }^{19}$ Studies on fibroblasts from 'normal' individuals, entailing the construction of dose-survival curves, have shown statistically signifi-

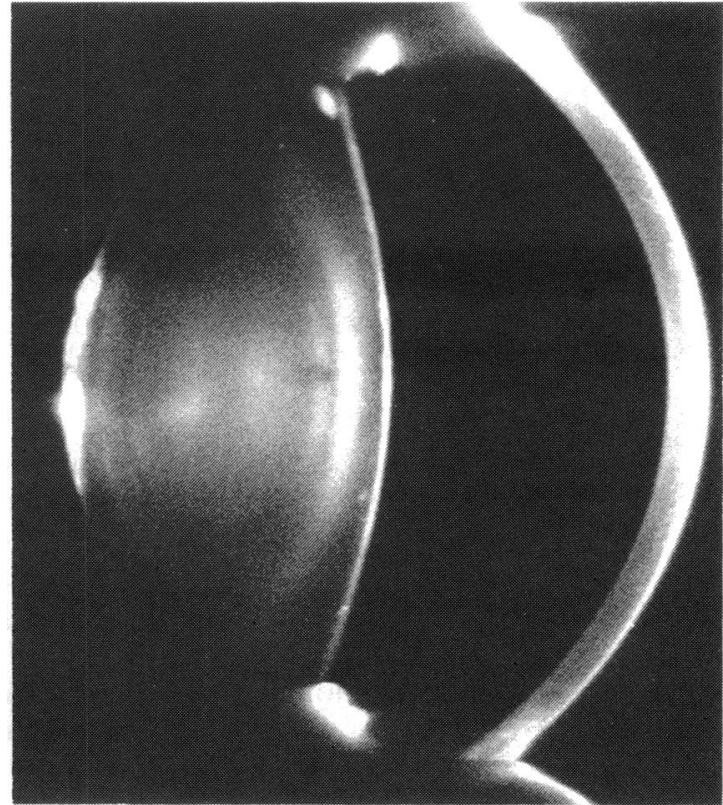

Fig. 2 The same eye as in Fig. I photographed on a slitimage camera.

cant differences of almost $100 \%$ between Do* values for least and most sensitive persons. ${ }^{2121}$ Individual variation to $x$ ray induced DNA damage can thus be determined. An abnormally low (highly radiosensitive) Do value has been shown in patients with severe normal tissue reactions to therapeutic radiation. ${ }^{22}$

To test the theory that naturally occurring subcapsular cataract might be related to abnormal radiation sensitivity we set out to examine the cellular radiosensitivity of patients with subcapsular cataract of no known cause and in those patients in whom it was suggested that subcapsular cataract had occurred as a result of exposure to small doses of radiation. This latter group of patients included all those personnel known to us who had attended the Christmas Island atomic weapon testing in the 1950s and who had subsequently developed cataract before the age of 60 . It had been suggested that the prevalence of cataract in these personnel was greater than should be expected and that the cataract might

*The expected survival was calculated as: $\log S_{\times x p}=\log \left[c\left\{1-\left(1-e^{D / D n}\right)^{n}\right\}\right]$,

where $D$ is the gamma radiation dose, Do is the reciprocal of the slope, and $\mathrm{n}$ the extrapolation number. The term $\mathrm{c}$ is included so that the expected surviving fraction is not constrained to $10 \% \%$ at zero dose. 
be the result of radiation received in Christmas Island.

\section{Materials and methods}

OPHTHALMIC

The patients were divided into three groups.

Group A. Christmas Island veterans (16 patients) known from our records of a previous study, or notified to us by the Christmas Island Veterans Association, who were thought to have cataracts, were invited to partake in the study.

Group B. Presenile PSC (11 patients) who were attending the Oxford Eye Hospital and had pure PSC of no identifiable aetiology. Of these, five had worked in environments where they might have been exposed to low levels of radiation.

Group C. Controls (six subjects) were chosen from an age matched population of fit healthy male volunteers with no past history of significant medical or ophthalmic complaints. Any control with any degree of cataract or an anterior clear zone not equal to grade 3 was rejected.

For the better understanding of the results the Christmas Island veterans were further subdivided into three groups. Group 1A (six patients) were those who were found on examination to have PSC (two patients), or aphakes (four patients), who had been noted by an ophthalmologist in the past to have PSC. Group 1B (six patients) were those who on examination did not have PSC. One of these patients was a unilateral aphake in whom the type of cataract previous to surgery was unknown. Group 1C (four patients) were those who had had cataract extractions, but in whom the type of cataract was unknown.

All patients and controls gave informed consent to the study.

\section{OPHTHALMIC EXAMINATION}

A full medical and ophthalmic history was obtained with particular reference to exposure to radiation. In the past history we specifically asked about all factors that are known to be associated with the causation, or with the avoidance of cataract ${ }^{23}$ : diabetes, renal or hepatic failure, hypertension, and carcinoma or leukaemia. The use of alcohol or tobacco or of any medication, especially steroids, analgesics, diuretics, nifedipine, and allopurinol, was inquired about. Patients were asked about eye injuries and ophthalmic surgery or medication taken. All patients were refracted, and the visual acuity was recorded by the Log MAR Ferris chart. Pupils were dilated with G phenylephrine $10 \%$ and $G$ tropicamide $1 \%$, repeated at least once in order to achieve a pupil size of $8 \mathrm{~mm}$. In addition to a full ophthalmic examination the lenses were graded by the same observer using the
Oxford Clinical Cataract Classification System..$^{24}$ The lenses were also photographed with the Brown slitimage camera and the Oxford retroillumination camera..$^{25}$ Blood for a random blood sugar was taken, and a further $60 \mathrm{ml}$ of blood was taken and placed in heparin without preservatives. A small $3 \times 3 \mathrm{~mm}$ sample of skin from the patient's forearm was taken under local anaesthetic. Blood samples and skin biopsies were then examined in a coded fashion within 24 hours.

\section{RADIATION SENSITIVITY}

The radiation sensitivity of lymphocyte DNA was tested at the Hammersmith Hospital by the method of buoyant density centrifugation as already described..$^{226-28}$ The radiation sensitivity by clonal assay for cell survival was measured at the MRC Cell Mutation Unit by means of skin derived fibroblasts $^{29.31}$ and T lymphocytes. ${ }^{31}$

\section{Results}

Table 1 shows the results in the controls and patients who were examined, with a brief description of the type of cataract or of other eye disease that was found.

There were 16 patients who had been present at Christmas Island. Of these PSC was found in two at the time of examination and believed from the hospital records to have been present in four others, making six cases in all. There were three others with cataract of unknown type, making it possible that there were a total of nine cases of PSC.

The history was not significant in suggesting alternative causes for cataract.

Eleven patients were examined who had not been to Christmas Island and had PSC. Of these, five had possible exposure to radiation at work.

The percentage number of hypersensitive samples of lymphocytes, as tested by buoyant density centrifugation at the Hammersmith Hospital, for all the individuals in the present study was 16 , that is, intermediate between those in the other two studies $^{2728}$ tested by the same methods. The mean age in the present study, 53.8, was intermediate between the mean ages of the individuals in the previous two studies of 38.6 (5\% hypersensitive population $\left.{ }^{27}\right)$ and $79 \cdot 7\left(26 \%\right.$ hypersensitive population $\left.{ }^{2 *}\right)$, thus showing a relationship with age but not with subcapsular cataract.

The data on radiation sensitivity, as measured in lymphocytes by buoyant density centrifugation and in fibroblasts and $\mathrm{T}$ lymphocytes by clonal assay, was analysed by the statistical package GLIM (Royal Statistical Society, London). No patient with PSC was found to be hypersensitive to radiation when the 
Table 1 Relation of cataract to radiation sensitivity

\begin{tabular}{|c|c|c|c|c|c|c|}
\hline & Age & $\%$ Repair & $\begin{array}{l}\text { Lymphe } \\
\text { Do }\end{array}$ & $\begin{array}{c}o \text { Fibro } \\
\text { Do }\end{array}$ & Reye & Leye \\
\hline \multicolumn{7}{|c|}{ Group IA Christmas Island with posterior subcapsular cataracts } \\
\hline 01 & 63 & 0 & 1.44 & $1 \cdot 62$ & PSC & $(?)$ \\
\hline 01 & 51 & $69 \cdot 5$ & $1 \cdot 30$ & 1.68 & (PSC) & (PSC) \\
\hline 03 & 50 & $61 \cdot 4$ & 1.62 & $1 \cdot 50$ & (PSC) & (PSC) \\
\hline 04 & 54 & 100 & $1 \cdot 71$ & & (PSC) & (PSC) \\
\hline 05 & 49 & $60 \cdot 9$ & 1.59 & 1.58 & Clear & (PSC) \\
\hline 06 & 52 & $36 \cdot 8$ & $1 \cdot 51$ & $1 \cdot 51$ & (PSC) & PSC \\
\hline \multicolumn{7}{|c|}{ Group IB Christmas Island without posterior subcapsular } \\
\hline 07 & 63 & 50 & 1.77 & 1.43 & N Brun & N Brun \\
\hline 08 & 51 & $85 \cdot 7$ & 1.55 & & Spoke & Spoke \\
\hline 09 & 50 & $51 \cdot 3$ & 1.52 & $1 \cdot 48$ & ASC & $(?)$ \\
\hline 10 & 49 & $59 \cdot 5$ & $1 \cdot 60$ & 1.69 & Mature & Spoke \\
\hline 11 & 50 & 12 & 1.95 & & Focal dot & Ret. Detach. \\
\hline 12 & 55 & $27 \cdot 3$ & 1.59 & 1.57 & Clear & Clear \\
\hline 13 & 50 & & & $1 \cdot 15$ & Clear & Clear \\
\hline \multicolumn{7}{|c|}{ Group IC Christmas Island with cataract of unknown type } \\
\hline 14 & 53 & () & $1 \cdot 42$ & 1.67 & Clear & $(?)$ \\
\hline 15 & 52 & $63 \cdot 8$ & $1 \cdot 42$ & & (Mature) & clear \\
\hline 16 & 51 & 53 & $1 \cdot 32$ & $1 \cdot 33$ & $(?)$ & $(?)$ \\
\hline \multicolumn{7}{|c|}{ Group B Non-Christmas Island with posterior subcapsular cataract } \\
\hline 17 & 50 & $76 \cdot 5$ & 1.55 & 1.15 & & \\
\hline 18 & 60) & $70 \cdot 4$ & 1.47 & $1 \cdot 21$ & & \\
\hline 19 & 62 & $64 \cdot 8$ & 1.50 & & & \\
\hline 20) & 54 & 20) & 1.21 & 1.67 & & \\
\hline 21 & 53 & $44 \cdot 4$ & & $1 \cdot 44$ & & \\
\hline 22 & 58 & 100 & 1.22 & 1.28 & & \\
\hline 23 & 32 & $67 \cdot 7$ & 1.61 & $1 \cdot 35$ & & \\
\hline 24 & 56 & $82 \cdot 4$ & 1.49 & & & \\
\hline 25 & 51 & & $2 \cdot 40$ & & & \\
\hline 26 & 58 & & $1 \cdot 28$ & $1 \cdot 51$ & & \\
\hline 27 & 39 & & 1.82 & $1 \cdot 40$ & & \\
\hline \multicolumn{7}{|c|}{ Group C Normal controls } \\
\hline 28 & 52 & $59 \cdot 1$ & 1.92 & 1.56 & & \\
\hline 29 & 50 & 53 & $1 \cdot 38$ & & & \\
\hline 30 & 52 & $62 \cdot 2$ & & $1 \cdot 36$ & & \\
\hline 31 & 56 & $55 \cdot 2$ & 1.27 & $1 \cdot 19$ & & \\
\hline 32 & 54 & $59 \cdot 1$ & $1 \cdot(07$ & 1.36 & & \\
\hline 33 & 49 & $64 \cdot 8$ & 1.76 & & & \\
\hline
\end{tabular}

$\%$ Repair $=\%$ lymphocyte DNA repair after irradiation tested at the Hammersmith Hospital.

Lympho (fibro) Do=Survival of lymphocyte (fibroblast) cell culture (Gy); as tested at the MRC Cell Mutation Unit.

Parentheses indicate an aphakic eye - that is, (PSC) means an aphakic eye which had a PSC according to notes available, which may be misleading in certain cases. (?) Means aphake with no record of type of cataract.

ASC=anterior subcapsular cataract. PSC=posterior subcapsular cataract. $\mathrm{N}$ Brun $=$ nuclear brunescence. Spoke $=$ spoke cataract.

results were compared with those from the study controls. In addition, in the clonal assays the results were compared with those from concurrent laboratory controls used in every experiment, and again no significant differences were observed. The observations on clonal survival will be reported in detail elsewhere.

\section{Discussion}

Approximately 18000 personnel were present at the UK atmospheric nuclear weapon test programme at Christmas Island between 1952 and 1967, and of these 1000 are believed to have died, leaving 17000 remaining. ${ }^{32}$ In these tests radioactive material was dispersed into the atmosphere, and they were followed by a clean-up operation. Attention was drawn to an apparent excess incidence of cancer in this group ${ }^{33}$ (this has subsequently not been confirmed ${ }^{32}$ ). It appeared from information reaching us at Oxford that there might also be an excess incidence of cataract in this group, since we had information before beginning our present study of 26 cases believed to be of PSC, being $0 \cdot 15 \%$ of the sample of 17000 . Our present study shows that we have knowledge of only 12 cases of cataract (an incidence of $0.07 \%$ ), and of these only six are of the PSC type that might be attributed to radiation. The mean age at examination of these cataract cases is 57 years, which falls into the age range in which cataract is uncommon. The frequency of cataract extraction for males in the age range of $40-49$ in Oxford is $0.003 \%$ rising to $0.023 \%$ at ages $50-59 .{ }^{3+}$ These figures relate to cataract extraction, and the prevalence of early cataract is necessarily higher than this. Senile cataract was reported in $3.5 \%$ of persons under the age of $65 .{ }^{35}$ Thus the incidence of cataract now known in the Christmas Island personnel of $0.07 \%$ is not more than expected. There will be cases that have not been brought to our attention, but there is no evidence that the incidence of cataract in the Christmas Island personnel exceeds the normal.

Subcapsular cataract is the least common of the three major types of cataract (cortical, nuclear, and subcapsular), and the stated proportion of cataracts that are subcapsular varies widely in different series, being reported as $6 \%,{ }^{36} 10 \%,{ }^{37} 24 \%,{ }^{36}, 40 \%,{ }^{34}$ and $50 \%{ }^{35}$ in western studies and as only $1 \%$ in the Punjab." These figures are for patients of all ages, and the proportion of PSC may be higher in younger people. ${ }^{3 *}$ Thus the proportion of PSC in the Christmas Island personnel, being $50 \%$ of those known to have cataract, is an expected value, and the minimum overall prevalence of PSC at $0 \cdot 04 \%$ of the Christmas Island personnel fits within the reported range. There is therefore no indication of any excess prevalence of subcapsular cataract that would indicate a radiational cause in the Christmas Island personnel.

Radiation sensitivity testing by the three methods now reported showed inconsistent results between the systems. The Do values for cell killing obtained by means of skin derived fibroblasts or T lymphocytes obtained from blood samples showed no significant differences between the groups of individuals tested. 
The postirradiation repair of lymphocyte DNA did show marked differences between individuals, but the occurrence of a low figure for repair was unrelated to the development of subcapsular cataract.

\section{CONCLUSION}

Radiation sensitivity, as tested by the methods used in this study, is unrelated to the development of cataract.

This work was supported in part by an award from the Wellcome Trust and in part by EC Grant BI6-0142-UK(H). We thank Professor B A Bridges for many useful discussions, Dr M H L Green for undertaking the computer analysis of radiation sensitivity data, and S A Harcourt for technical support.

\section{References}

1 Weekers R, Delmarcelle J, Luyckx-Bacus J, Collignon J. Morphological changes of the lens with age and cataract. In: The human lens in relation to cataract. Ciba Foundation Symposium, 1973: $25-40$.

2 Brown N. Lens changes with age and cataract. In: The human lens in relation to cataract. Ciba Foundation Symposium, 1973: 65-71.

3 Brown N. Photographic investigation of the human lens and cataract. Surv Ophthalmol 1979; 23: 307-17.

4 Brown N, Tripathi R. Loss of the anterior subcapsular clear zone of the lens. Prognostic significance in cataract formation. Trans Ophthalmol Soc UK 1974: 94: 29-45.

5 Perkins ES. Lens thickness in early cataract. Br J Ophthalmol 1988: 72: 348-53.

6 Harding JJ, Crabbe MJC. The lens: development, proteins, metabolism and cataract. In: Davson $\mathrm{H}$, ed. The eye. 3 rd ed. 1984: 1b: chapter 3 .

7 Fisher RF. The lens in uveitis. Trans Ophthalmol Soc UK 1981; 101: 317-20.

8 Scott JD. Lens changes in retinal detachment. Trans Ophthalmol Soc UK 1979; 99: 241-3.

9 Brown N. The lens, cataract and its management. In: Peyman GA, Sanders DR, Goldberg MF, eds. Principles and practise of ophthalmology. Philadelphia: Saunders, 1980: 495-526.

10) Greiner JV, Chylack LT. Posterior subcapsular cataracts. Histopathologic study of steroid-associated cataracts. Arch Ophthalmol 1979; 97: 135-44.

11 Merriam GR, Szechter A, Focht EF. The effects of ionizing radiation on the eye. Front Radiat Ther Oncol 1972; 6: 346-8.

12 Brown N, Roth J, Catterall M, Beal A. The effect of fast neutron radiation on the human eye. A preliminary communication. Br J Ophthalmol 1975; 59: 510-3.

13 Roth J, Brown N, Catterall M, Beal A. The effect of fast neutron radiation on the human eye. Br J Ophthalmol 1976; 60: 236-44.

14 Hayes PB, Fisher RF. Influence of a prolonged period of lowdosage of $x$ rays on the optic and ultrastructural appearance of cataract of the human lens. Br J Ophthalmol 1979; 63: 457-64.

15 Griffith TP, Pirie A. Vaughan J. Possible cataractogenic effect of radionuclides deposited within the eye from the blood stream. Br J Ophthalmol 1985; 69: 219-27.

16 Cogan D, Donaldson D. Clinical and pathological characteristics of radiation cataract. Arch Ophthalmol 1952; 47: 55-70.

17 Charles MW, Brown N. Dimensions of the human eye relevant to radiation protection. Phys Med Biol 1975; 20: 202-18.

18 Manabe S, Bucala R, Cerami A. Non enzymatic addition of glucocorticoids to lens protein in steroid induced cataracts. J Clin Invest 1984: 74: 1803-10.
19 Taylor AMR, Harnden DG, Artlett CF, et al. Ataxiatelangiectasia: a human mutation with abnormal radiosensitivity. Nature 1975; 258: 427-9.

20 Weichselbaum RR, Nove J, Little JB. $X$-ray sensitivity for fiftythree human diploid fibroblast cell strains from patients with characterised genetic disorders. Cancer Res 1980; 40: 920-5.

21 Arlett CF, Harcourt SA. Survey of radiosensitivity in a variety of human cell strains. Cancer Res 1980; 40: 926-32.

22 Sabovljev SA, Cramp WA, Lewis PD, Harris G, Halnan KE, Lambert $J$. Use of rapid tests of cellular radiosensitivity in radiotherapeutic practice. Lancet 1985; ii: 787.

23 Harding JJ, van Heyningen R. Epidemiology and risk factors for cataract. Eye 1987; 1: 537-41.

24 Sparrow JM, Bron AJ, Brown NAP, Ayliffe W, Hill AR. The Oxford clinical cataract classification and grading system. Int Ophthalmol 1986; 9: 207-25.

25 Brown NAP, Bron AJ, Ayliffe W, Sparrow JM, Hill AR. The objective assessment of cataract. Eye 1987; 1: 234-46.

26 Chamberlain S, Lewis PD. Studies of cellular hyperpersensitivity to ionizing radiation in Friedreich's ataxia. $J$ Neurol Neurosurg Psychiatry 1982; 45: 1136-8.

27 Harris G, Cramp WA, Edwards JC, et al. Radiosensitivity of peripheral blood lymphocytes in autoimmune disease. Int J Radiat Biol 1985; 47: 689-99.

28 Harris G, Holmes A, Sabovljev SA, et al. Sensitivity to $x$ irradiation of peripheral blood lymphocytes from ageing donors. Int J Radiat Biol 1986; 50: 685-94.

29 Arlett CF. The radiosensitivity of cultured human cells. In: Fielden EM, Fowler JF, Hendry JH, Scott D, eds. Radiation Research Vol 2. Proceedings of the 8th International Congress of Radiation Research, Edinburgh, July 1987. London: Taylor and Francis, 1988: 424-30.

30 Arlett CF, Green MHL, Priestley A, Harcourt SA, Mayne LV. Comparative human cellular radiosensitivity: 1 The effect of SV40 transformation and immortalisation on the gammairradiation survival of skin derived fibroblasts from normal individuals and from ataxia-telangiectasia patients and heterozygotes. Int J Radiat Biol 1988; 54: 911-28.

31 Cole J, Arlett CF, Green MHL, et al. Comparative human cellular radiosensitivity: II. The survival following gammairradiation of unstimulated (Go) T-lymphocytes, T-lymphocyte lines, lymphoblastoid cell lines and fibroblasts from normal donors, from ataxia telangiectasia patients and from ataxiatelangiectasia heterozygotes. Int J Radiat Biol 1988; 54: 929-43.

32 Darby CS, Kendall GM, Fell TP, et al. Mortality and cancer incidence in $U K$ participants in $U K$ atmospheric nuclear weapon tests and experimental programmes. NRCB-R214. London: HMSO, 1988.

33 Knox EG, Sorahan T, Stewart AM. Cancer following nuclear weapon tests. Lancet 1983 ; i: 815 .

34 Caird F, Pirie A, Ramsell TG. Diabetes and the eye. Oxford: Blackwell, 1969: 129-32.

35 Krueger DE, Milton R, Maunder LR. The Framingham eye study: introduction to the monograph. Surv Ophthalmol 1980; 24: $614-20$.

36 Foster $\mathrm{J}$, Benson $\mathrm{J}$. The percentage incidence and surgical significance of the different forms of senile cataract. Trans Ophthalmol Soc UK 1934; 54: 127-36.

37 Kirby DB. Pathogenesis of senile cataract. Arch Ophthalmol 1932: 8: 96-119.

38 Brown NAP, Hill AR. Cataract: the relationship between myopia and cataract morphology. Br J Ophthalmol 1987; 71: 405-14.

39 Perkins ES. Cataract: refraction error, diabetes, and morphology. Br J Ophthalmol 1984; 68: 293-7.

40 Chatterjee A, Milton RC, Thyle S. Prevalence and aetiology of cataract in Punjab. Br J Ophthalmol 1982; 66: 35-42.

Accepted for publication 2 August 1989. 